\title{
Effect of Pulsed Laser Power Annealing on Structural and Optical Characteristics of ZnSe Thin Films
}

\author{
S.A. Aly ${ }^{a, *}$, AlaA A. AKL ${ }^{a, b}$ AND H. HOWARI ${ }^{c, d}$ \\ ${ }^{a}$ Physics Department, Faculty of Science, Minia University, Minia, Egypt \\ ${ }^{b}$ Faculty of Science in Ad-Dawadmi, Physics Department, Shaqra University, 11911, Kingdom of Saudi Arabia \\ ${ }^{c}$ Deanship of Educational Services, Qassim University, Kingdom of Saudi Arabia \\ ${ }^{d}$ Physics Department, Faculty of Science, Al-Baath University, Homs, Syria \\ (Received March 19, 2014; revised version April 11, 2015; in final form August 4, 2015) \\ Samples of ZnSe of the same film thickness $(320 \mathrm{~nm})$ have been thermally evaporated on unheated quartz \\ substrates using high purity powder. The prepared films were subjected to pulsed laser annealing of two different \\ powers. X-ray diffraction studies revealed that the as-deposited samples were polycrystalline cubic (zinc-blende \\ type) structure. As the annealing power increases, the crystallinity of ZnSe films was improved with preferential \\ orientation along the (111) direction parallel to the substrate surface. Microstructural characterizations have been \\ evaluated using the Debye-Scherrer formula. The absorption coefficient as well as the energy gap for the as- \\ deposited and the annealed samples were also reported.
}

DOI: 10.12693 /APhysPolA.128.414

PACS: 81.15.-z, 68.55.jd, 68.55.ag, 78.70.Ck, 81.15.Dj, 78.20.-e

\section{Introduction}

Semiconductors are essential materials in electronic device fabrication such as diodes, laser diodes (LD), light emission diodes (LED), sensors, solar cells, thermoelectric devices [1-6]. Binary semiconductors are considered as important technological materials because of their potential applications in optoelectronic devices, solar cells, IR detectors and lasers $[7,8]$. Binary compounds of group IIB and group VIA elements, commonly referred to as II-VI compounds, have technologically important applications. Among these compounds, only cadmium telluride $(\mathrm{CdTe})$ and zinc selenide $(\mathrm{ZnSe})$ can be prepared in both $n$ - and $p$-type forms [9].

Recently, a-ZnSe and c-ZnSe thin films prepared by various methods including RF magnetron sputtering [10], pulsed laser [11], atomic layer deposition [12], wet chemical path deposition [13], quasi-closed volume technique [14] were investigated.

Some studies were done on the crystalline microstructure changes of ZnSe films. The structure of the $\mathrm{ZnSe}$ layer depends on the synthesis process type, deposition parameters [15], substrate temperature [16, 17], annealing temperature $[18,19]$ or composition ratio of $\mathrm{ZnSe}[20]$.

The band-gap energy is a very important property of the semiconductor and depends greatly on the material structure. Many papers show the correlation of the band gap with near-surface layer structure changes of ZnSe [20-22]. They also show that control of the polycrystallites size and thus control of the change of band gap is difficult for all processes.

*corresponding author; e-mail: saaly61@hotmail.com
Pulsed laser annealing (PLA) is used to modify the surface layer, i.e. to remove the damage created after implantation process $[23,24]$, to change the structure from amorphous to polycrystalline [25] or to improve the crystal structure [26, 27]. Choosing an appropriate value of the deposited energy and the size of the illuminated area makes the PLA a well-controlled technique.

In a previous work, the effect of PLA on the dispersion properties of ZnSe films is studied [25].

In the present work, the influence of PLA on the structural characteristics of ZnSe films deposited using thermal evaporation technique is studied. The structure of ZnSe films has been investigated by X-ray diffraction (XRD) technique. The influence of PLA with different values of pulse power on the optical parameters such as absorption coefficient as well as energy gap of the investigated films is also presented.

\section{Experimental details}

ZnSe thin films were deposited on unheated quartz substrates using a high purity ZnSe powder by thermal evaporation technique using Edwards coating unit (Model E306A). The heating filament was a conventional tungsten boat. In order to prevent scattering during deposition, the powder was pressed at $100 \mathrm{~kg} / \mathrm{cm}^{2}$ into a pellet with a diameter of $10 \mathrm{~mm}$ and several $\mathrm{mm}$ in thickness. The pressure was brought down until a vacuum of about $8.2 \times 10^{-4} \mathrm{~Pa}$ was achieved. Film thicknesses were measured using the quartz crystal oscillator. The thickness of the used samples was about $320 \mathrm{~nm}$.

Prepared samples was subjected to annealing using $\mathrm{CO}_{2}$ pulsed laser provided with $q$-switch (single pulse) at a wavelength of $10600 \mathrm{~nm}$ with two different laser powers (20 and $30 \mathrm{~W}$ ). The laser pulse is focused onto different spots until the whole sample is completely annealed. 
Film structure was examined by XRD using JEOL X-ray diffractometer type JSDX-60PA with a $\mathrm{Cu} K_{\alpha^{-}}$ radiation $(\lambda=0.15418 \mathrm{~nm})$ was used with a slow scanning rate $\left(1^{\circ} / \mathrm{min}\right)$. XRD was performed for the phase identification and preferred orientation determination.

Transmittance and reflectance spectra of the prepared samples were carried out at room temperature in the spectral range from 280 to $800 \mathrm{~nm}$ using Jasco V-570 UV-VIS-NIR double beam spectrophotometer. All optical measurements have been performed at room temperature $(300 \mathrm{~K})$.

\section{Results and discussion}

\subsection{ZnSe structure analysis}

XRD pattern of as-deposited ZnSe films and those annealed at different laser power is depicted in Fig. 1. It is observed that the XRD patterns show a major peak at $2 \theta=27.20^{\circ}$ (111) for all the films. Also, an appearance of two other peaks in XRD pattern at $2 \theta=45.25^{\circ}(220)$ and $52.16^{\circ}(311)$ for the samples annealed at power of 20 and $30 \mathrm{~W}$, respectively. It can be observed that the peaks intensity increases with increasing power of the annealing laser beam.

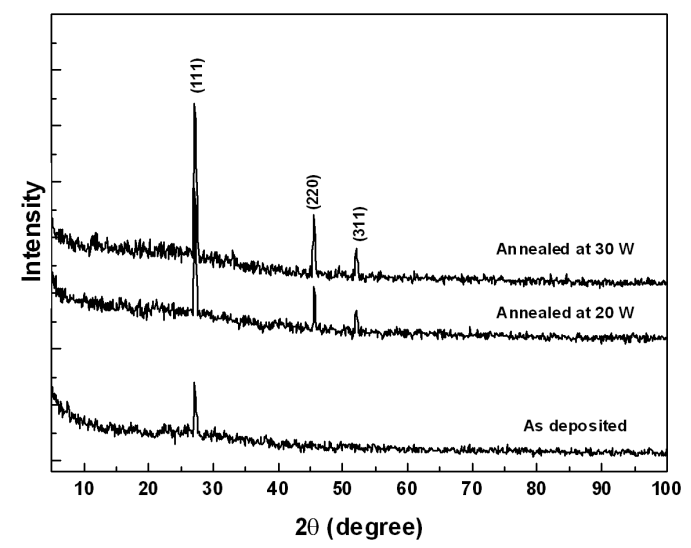

Fig. 1. X-ray diffraction pattern of as-deposited ZnSe thin film and two samples annealed at laser powers of 20 and $30 \mathrm{~W}$.

Similar change of the structure to cubic zinc blende has been shown for the ZnSe films annealed at low temperature [19, 28-31].

The results from XRD patterns were used to calculate the average crystallite size $(D)$, the lattice spacing $(d)$, the lattice parameter $(a)$, the dislocation density $(\delta)$, and the strain $(\varepsilon)$.

The crystallite size, $D$, has been calculated using the Debye-Scherrer formula [32]:

$$
D=\frac{0.94 \lambda}{\beta \cos \theta},
$$

where $\beta$ is the full-width at half-maximum (FWHM), $D$ is the crystallite size value and $\mathrm{q}$ is the angle between the incident and the scattered X-ray. As shown in Table I, the crystallite size value increases from $28.14 \pm 2 \mathrm{~nm}$ for the as-deposited sample to $3685 \pm 2$ and $43.76 \pm 2 \mathrm{~nm}$ for the samples annealed at PLA of 20 and $30 \mathrm{~W}$ annealing power, respectively. The increase in crystallite size with the annealing laser power may be due to the coalescence of small crystals.

The Bragg formula was used to calculate the lattice spacing [32]:

$$
d=\frac{\lambda}{2 \sin \theta} .
$$

The lattice parameter was determined by using relation [32]:

$$
\frac{1}{d^{2}}=\frac{h^{2}+k^{2}+l^{2}}{a^{2}},
$$

where $h, k$, and $l$ represent the lattice planes.

The dislocation density, $\delta$, defined as the length of dislocation lines per unit volume, has been estimated using the following equation [33, 34]:

$$
\delta=\frac{1}{D^{2}} .
$$

It is known that the calculated value of $\delta$ is attributed to the amount of defects in a crystal growth of ZnSe thin films. The number of crystallites per unit area $(N)$ and the microstrain $(\varepsilon)$ of $\mathrm{ZnSe}$ thin films were calculated employing the measured value of crystallite size $(D)$ by the following relations [35]:

$$
\begin{aligned}
& N=\frac{t}{D^{3}}, \\
& \varepsilon=\frac{\beta \cos \theta}{4},
\end{aligned}
$$

where $t$ is the film thickness $(320 \mathrm{~nm})$.

Table I shows the values of the structural properties of the ZnSe thin films. As shown in Table I, the evaluated values of the dislocation density of $\mathrm{ZnSe}$ thin films are ranged from $1.26 \times 10^{15}$ for the deposited sample to $5.22 \times 10^{14}$ lines $/ \mathrm{m}^{2}$ for the sample annealed at PLA of $30 \mathrm{~W}$. Also, the microstrain was varied from $1.287 \times 10^{-3}$ to $8.279 \times 10^{-4}$ for the as-deposited sample and the sample annealed at PLA of $30 \mathrm{~W}$, respectively. The microstrain is equivalent to variations in the $d$-spacing within domains by an amount depending on the elastic constants of the material and the nature of internal stresses.

The small values of $\delta$ obtained in the present study confirm the good crystallinity of the thin films fabricated by the thermal evaporation technique. On the other hand, the number of crystallites per unit area $(N)$ was found to be $1.436 \times 10^{16}$ for the as-deposited sample and $3.818 \times 10^{15}$ crystallites $/ \mathrm{m}^{2}$ for the sample annealed at PLA of $30 \mathrm{~W}$.

These results are in good agreement with the data obtained in another studies of annealed ZnSe films structure $[19,35-37]$. The calculated values of structural parameters are shown in Table I. 
The structural parameters and properties of $\mathrm{ZnSe}$ film at various powers of laser beam.

\begin{tabular}{c|c|c|c|c|c|c|c|c|c}
\hline \hline Sample & $\begin{array}{c}2 \theta \\
{[\mathrm{deg}]}\end{array}$ & $h k l$ & $\begin{array}{c}\beta \\
{[\mathrm{deg}]}\end{array}$ & $\begin{array}{c}d \\
{[\AA]}\end{array}$ & $\begin{array}{c}a \\
{[\AA]}\end{array}$ & $\begin{array}{c}D \\
{[\AA]}\end{array}$ & $\begin{array}{c}N \times 10^{15} \\
{\left[\text { crystalline } / \mathrm{m}^{2}\right]}\end{array}$ & $\begin{array}{c}\varepsilon \times 10^{-3} \\
{\left[\text { [ine }{ }^{-2} \mathrm{~m}^{-4}\right]}\end{array}$ & $\begin{array}{c}\delta \times 10^{15} \\
{\left[\text { lines } / \mathrm{m}^{2}\right]}\end{array}$ \\
\hline as-deposited & 27.22 & $(111)$ & 0.304 & 3.276 & 5.674 & 281.42 & 14.30 & 1.29 & 1.26 \\
\hline annealed & 27.24 & $(111)$ & 0.231 & 3.274 & 5.671 & & & & \\
by 20 W & 45.25 & $(220)$ & 0.244 & 2.004 & 5.668 & 368.54 & 6.39 & 1.06 & 0.74 \\
& 52.16 & $(311)$ & 0.251 & 1.753 & 5.814 & & & & \\
\hline \multirow{2}{*}{ annealed } & 27.26 & $(111)$ & 0.195 & 3.271 & 5.666 & & & 0.83 & 0.52 \\
by 30 W & 45.26 & $(220)$ & 0.206 & 2.003 & 5.667 & 437.60 & 3.81 & &
\end{tabular}

\subsection{Optical measurements}

\subsubsection{Transmittance and reflectance measurements}

The spectral transmission $T(\lambda)$ and reflectance $R(\lambda)$ before (as-deposited state) and after annealing at two different pulsed laser power for ZnSe thin films are shown in Figs. 2 and 3. The PLA influence on the value of the transmission and reflectance is clearly visible. The overall transmittance and reflectance decreases after annealing, indicating an absorption of light. Moreover, all the investigated samples show an average high transparency. Also, it can be noticed that the transmittance behavior of all samples shows multiple interferences, which indicate that ZnSe thin films have moderate absorption coefficients and high film thickness. Also, the films showed a shift in the absorption edge towards shorter wavelength with increasing annealing power for both of transmittance and reflectance. This shift could be attributed to the structural changes in the film with the annealing process [38].

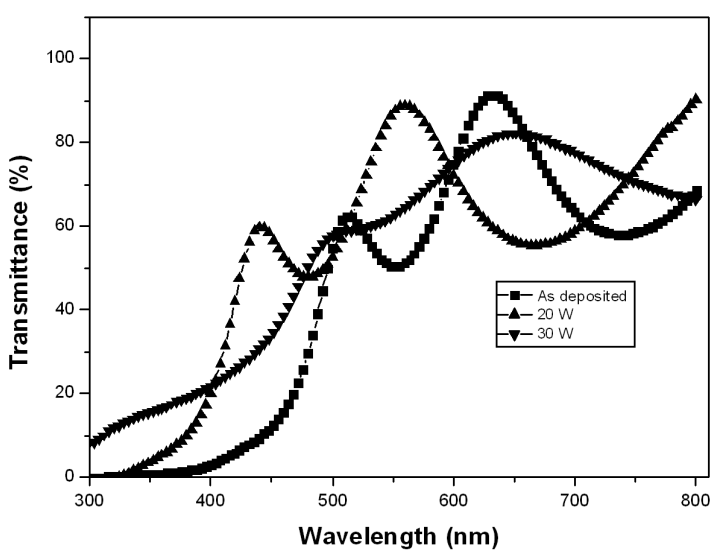

Fig. 2. Spectral transmission as a function of wavelength of as-deposited ZnSe sample and for two samples annealed at laser powers of 20 and $30 \mathrm{~W}$.

\subsubsection{The absorption coefficient}

The absorption coefficient $(\alpha)$ was calculated from the following relation [39]:

$$
\alpha=\frac{1}{t} \ln \frac{1-R(\lambda)}{T(\lambda)},
$$

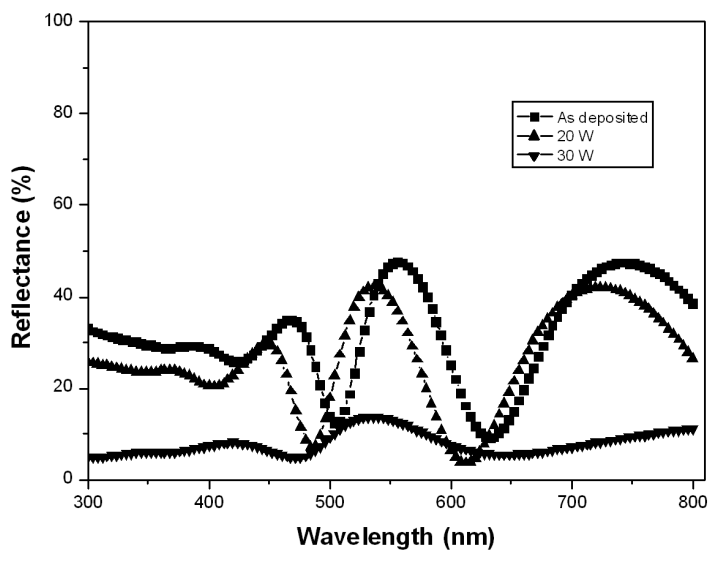

Fig. 3. Reflectance spectrum as a function of wavelength of as-deposited $\mathrm{ZnSe}$ sample and two samples annealed at laser powers of 20 and $30 \mathrm{~W}$.

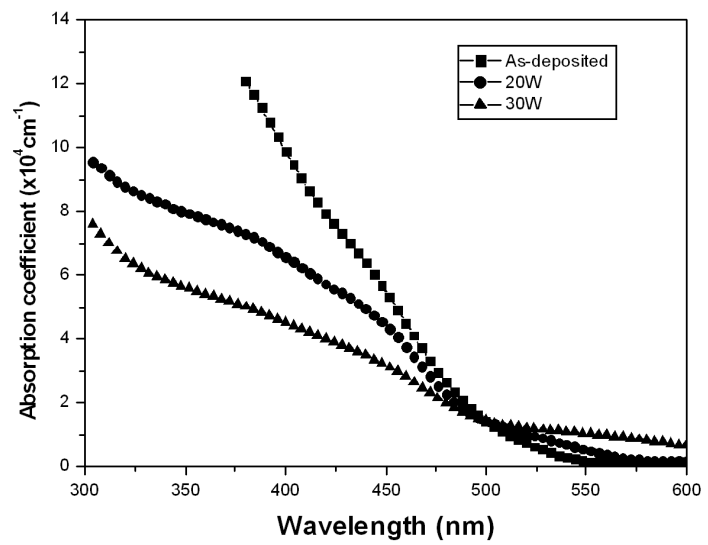

Fig. 4. Variation of absorption coefficient with wavelength for as-deposited ZnSe sample and after annealing at laser power of 20 and $30 \mathrm{~W}$.

where $R(\lambda)$ and $T(\lambda)$ are the spectral reflectance and transmittance at wavelength $\lambda$ and $t$ is the film thickness.

The dependence of absorption coefficient on wavelength has been investigated for the as-deposited sample as well as after PLA of 20 and $30 \mathrm{~W}$ is shown in Fig. 4. For wavelengths $\geq 550 \mathrm{~nm}$, no appreciable change was observed and the value of the absorption coefficient was 
very low for the two samples. For $\lambda \leq 500 \mathrm{~nm}, \alpha$ is strongly dependent on wavelength as a result of transition across the semiconductor band gap in ZnSe [20]. A dramatic increase in the absorption coefficient with decreasing wavelength is observed for the as-deposited sample. However, a slow and slower increase in the absorption coefficient with wavelength is obtained for the samples annealed at 20 and $30 \mathrm{~W}$, respectively.

\subsubsection{Determination of energy gap}

The optical energy gap $\left(E_{\mathrm{g}}\right)$ of the films was estimated from the optical measurements. The absorption coefficient was found to follow the relation:

$$
\alpha=\frac{A\left(h \nu-E_{\mathrm{g}}\right)^{n}}{h \nu},
$$

where $A$ is a constant and $n$ is a constant, equal to $1 / 2$ for direct band gap semiconductors.

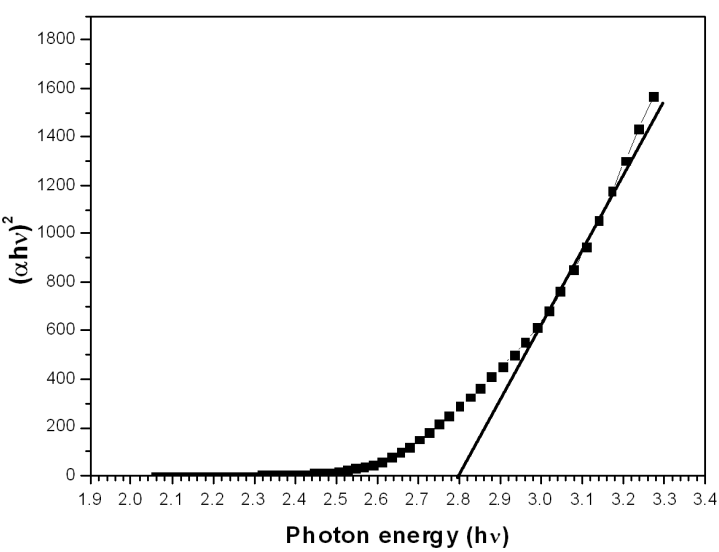

Fig. 5. $(\alpha h \nu)^{2}$ as a function of the photon energy $(h \nu)$ for the as-deposited ZnSe sample.

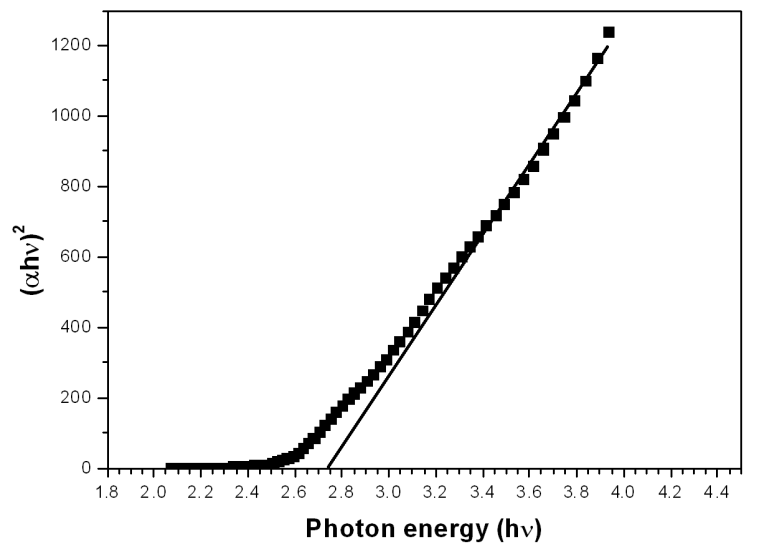

Fig. 6. $(\alpha h \nu)^{2}$ as a function of the photon energy $(h \nu)$ for a $\mathrm{ZnSe}$ sample annealed at a laser power of $20 \mathrm{~W}$.

The plots of $(\alpha h \nu)^{2}$ versus the photon energy $(h \nu)$ in the absorption region for the as-deposited and that annealed at PLA of $30 \mathrm{~W}$ indicate a direct allowed transition and are illustrated in Figs. 5-7. The energy gap can be determined from the extrapolation of the linear portion with the photon energy axis. It is noticed

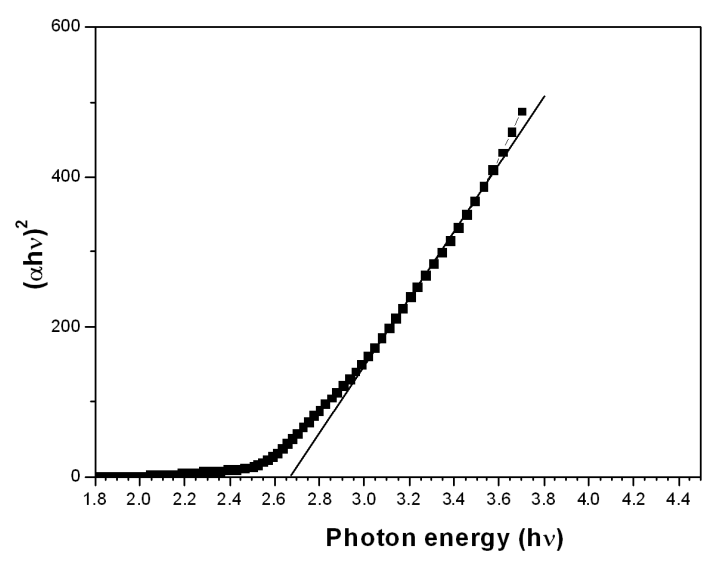

Fig. 7. (As in Fig. 6 but for laser power of $30 \mathrm{~W}$.

that the value of $E_{\mathrm{g}}$ is 2.8 for the as-deposited sample. However, the value of $E_{\mathrm{g}}$ was decreased by PLA annealing to 2.74 and $2.67 \mathrm{eV}$ for the samples annealed at 20 and $30 \mathrm{~W}$, respectively, which is close to that of the bulk material [40, 41].

The same behavior for the reduction of energy gap for thermally annealed ZnSe samples is obtained by PhaeNgam et al. [19]. They found that the energy gap is decreased from 2.72 to $2.69 \mathrm{eV}$ when the annealing temperature increased from $100^{\circ} \mathrm{C}$ to $300^{\circ} \mathrm{C}$, respectively.

TABLE II

Tabulation of crystalline size, dislocation density, band gap of as-deposited and laser annealed ZnSe films.

\begin{tabular}{c|c|c|c}
\hline \hline Sample & $\begin{array}{c}\text { Crystallites } \\
\text { size }[\AA]\end{array}$ & $\begin{array}{c}\text { Dislocation } \\
\text { density } \delta \\
{\left[\times 10^{15} \text { lines } / \mathrm{m}^{2}\right]}\end{array}$ & $\begin{array}{c}\text { Energy } \\
\text { gap }[\mathrm{eV}]\end{array}$ \\
\hline as-deposite & 281.42 & 1.26 & 2.8 \\
annealed by 20 W & 368.54 & 0.74 & 2.74 \\
annealed by 30 W & 437.60 & 0.52 & 2.67
\end{tabular}

The decrease in $E_{\mathrm{g}}$ value is possibly due to the increase in crystallite size and the decrease in the number of defects due to annealing as shown in Table II. It is known that pure semiconducting compounds have a sharp absorption edge (corresponding to forbidden energy band gap) $[42,43]$. The optical absorption edge shifts towards shorter wavelength. This shift may be due to the improvement of the crystalline structure transformation occurring with PLA. The increase in crystallinity can reduce the energy gap of the films $[44,45]$.

\section{Conclusions}

ZnSe thin films, deposited on quartz substrates by thermal evaporation technique, are polycrystalline and have a zinc-blende structure with preferred orientation along the (111) direction. PLA is a simple method used to anneal the films. After annealing, the film structure is improved and the orientation degree of crystallites increases. The crystallite size value increases from 
$28.14 \pm 2 \mathrm{~nm}$ for the as-deposited sample to $36.85 \pm 2$ and $43.76 \pm 2 \mathrm{~nm}$ for the samples annealed at PLA of 20 and $30 \mathrm{~W}$ annealing power.

An increase in the absorption coefficient for $\lambda \leq$ $500 \mathrm{~nm}$ is a result of transition across the semiconductor band gap in ZnSe. For wavelengths $>550 \mathrm{~nm}$ no appreciable change was observed.

The values of the optical band gap were determined from the absorption spectra. It was observed that the decrease in band gap energy was from $2.8 \mathrm{eV}$ for the as-deposited sample to 2.74 and 2.67 for the samples annealed at a PLA of 20 and $30 \mathrm{~W}$. This decrease in energy gap can be attributed to the increase in the grain size of the sample.

\section{References}

[1] K. Bourenane, A. Keffous, G. Nezzal, Vacuum 81, 663 (2007).

[2] G.V. Lokeswara, L. Reddy, R. Moorthy, T. Chengaiah, B.C. Jamalaiah, Adv. Mater. Lett. 4, 841 (2013).

[3] A. Szerling, P. Karbownik, A. Łaszcz, K. Kosiel, M. Bugajski, Vacuum 82, 977 (2008).

[4] N. Yamazoe, K. Shimanoe, Sensors Actuat. B Chem. 187, 162 (2013).

[5] N. Muthukumarasamy, S. Velumani, R. Balasundaraprabhu, R.C. Jayakumar, M.D. Kannan, Vacuum 84 , 1216 (2010)

[6] W. Phae-nam, V. Kosalathip, T. Kumpeerapun, P. Limsuwan, A. Dauscher, J. Appl. Sci. 11, 3625 (2011).

[7] G. Riveros, H. Gomez, R. Henriguez, R. Schrebler, R.E. Maratti, E.A. Dalchiele, Sol. Energy Mater. Sol. Cells 70, 255 (2001).

[8] V. Kumar, T.P. Sharma, Opt. Mater. 10, 253 (1998).

[9] L. Ting Chu, S.C. Shirley, Solid-State Electron. 38, 533 (1995).

[10] A. Rizzo, M.A. Tagliente, L. Caneve, S. Scaglione, Thin Solid Films 368, 8 (2000).

[11] B.H. Boo, N. Xu, J.K. Lee, Vacuum 64, 145 (2002).

[12] E. Guziewicz, M. Godlewski, K. Kopalko, E. Lusakowska, E. Dynowska, M. Guziewicz, M.M. Godlewski, M. Phillips, Thin Solid Films 446, 172 (2004).

[13] C. Mehta, G.S.S. Saini, J.M. Abbas, S.K. Tripathi, Appl. Surf. Sci. 256, 608 (2009).

[14] G.I. Rusa, M. Diciu, C. Pirghie, E.M. Popa, Appl. Surf. Sci. 253, 9500 (2007).

[15] M. Jun Kim, S. Ho Lee, H. Tak Kim, S. Ho Sohn, Mol. Cryst. Liq. Cryst. 586, 129 (2013).

[16] M.R.A. Bhuiyan, M.A.H. Miah, J. Begum, J. Bangladesh Acad. Sci. 36, 233 (2012).

[17] N.J. Suthan Kissinger, N. Velmurugan, K. Perumal, J. Korean Phys. Soc. 55, 1577 (2009).

[18] F.I. Ezema, A.B.C. Ekwealor, R.U. Osuji, Turk. J. Phys. 30, 157 (2006).
[19] W. Phae-Ngam, S. Suchat, T. Kumpeerapun, V. Kosalathip, Adv. Mater. Lett. 5, 496 (2014).

[20] M. Öztas, M. Bedir, O.F. Bakkaloğlu, R. Ormanci,

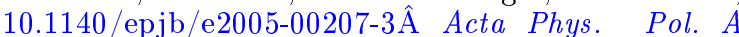
107, 525 (2005).

[21] C.A. Estrada, P.K. Nair, M.T.S. Nair, R.A. Zingaro, E.A. Meyers, J. Electrochem. Soc. 141, 802 (1994).

[22] C.D. Lokhande, P.S. Patil, H. Tributsch, A. Ennaoui, Sol. Energy Mater. Sol. Cells 55, 379 (1998).

[23] P. Bhattacharya, L.Y. Pang, Phys. Today 47, 64 (1994).

[24] R.A. Smith, Semiconductors, Cambridge University Press, Cambridge 1979, Ch. 10, p. 290.

[25] H. Howari, J. Natural Sci. Math. 5, 139 (2012).

[26] K.T. Ramakrishna Reddy, Y.V. Subbaiah, Thin Solid Films 431-432, 340 (2003).

[27] H. Howari, D. Sands, J.E. Nicholls, J.H.C. Hogg T. Stirner, W.E. Hagston, J. Appl. Phys. 88, 1373 (2000).

[28] R. Kumaresan, M. Ichimura, E. Arai, Thin Solid Films 414, 25 (2002).

[29] G.G. Rusu, V. Ciupina, M.F. Popa, G. Prodan, C. Baban, J. Non-Cryst. Solids 352, 1525 (2006).

[30] P.P. Hankare, P.A. Chate, P.A. Chavan, V.M. Bhuse, J. Mater. Sci. Mater. Electron. 20, 374 (2009).

[31] T.M. Khan, M. Zakria, M. Ahmad, R.I. Shakoor, J. Lumin. 147, 97 (2014).

[32] H.P. Klug, L.E. Alexander, X-ray Diffraction Procedures, Wiley, New York 1954.

[33] A. Kropidłowska, J. Chojnacki, A. Fahmi, B. Becker, Dalton Trans. 47, 6825 (2008).

[34] V. Bilgin, S. Kose, F. Atay, I. Akyuz, Mater. Chem. Phys. 94, 103 (2005).

[35] Z.R. Khan, M. Zulfequar, Mohd. Shahid Khan, Mater. Sci. Eng. B 174, 145 (2010).

[36] A.A. Yadav, M.A. Barote, T.V. Chavan, E.U. Masumdar, J. Alloys Comp. 509, 916 (2011).

[37] G.G. Rusu, M. Rusu, J. Optoelectron. Adv. Mater. 9, 321 (2007)

[38] M. Ashraf, S.M.J. Akhtar, A.F. Khan, Z. Ali, A. Qayyum, J. Alloys Comp. 509, 2414 (2011).

[39] F. Demichelis, G. Kaniadakis, A. Tagliferro, E. Tresso, J. Appl. Opt. 26, 1737 (1987).

[40] M.A. Russak, J. Reichman, J. Electrochem. Soc. 129, 542 (1982).

[41] O.V. Krylov, Catalysis by Nonmetals, Academic Press, New York 1970.

[42] E. Marques, J.B. Ramerez-Malo, P. Villares, R. Jimenez-Garay, R. Swanepoel, Thin Solid Films 254, 83 (1995).

[43] M. Nowak, Thin Solid Films 266, 258 (1995).

[44] A.K. Bhatnagar, K.V. Reddy, V. Srivastava, J. Phys. D Appl. Phys. 18, L149 (1985).

[45] V. Patil, S. Pawar, M. Chougule, P. Godse, R.S. Shashwati, P. Joshi, J. Surf. Eng. Mater. Adv. Technol. 1, 35 (2011). 